\title{
O direito de retrocessão em face do não atendimento à destinação do bem desapropriado ${ }^{1}$
}

\author{
Eloísa Cristina Werdenberg ${ }^{2}$ \\ Profa. Dra. Marlene Kempfer Bassoli ${ }^{3}$
}

\section{Resumo}

O presente trabalho é um estudo preliminar sobre o direito de retrocessão em face do não atendimento à destinação do bem desapropriado, voltando-se com maior detalhe para a eficácia do art. 35 do Dec. no 3.365/41. Seu principal objetivo é analisar a relação existente entre esse artigo e o direito que o particular possui de reaver o bem desapropriado, quando houver o desvio de finalidade.

Palavras Chave: Propriedade; Função Social; Desapropriação; Desvio de Finalidade; Retrocessão.

\section{Considerações iniciais}

Com a evolução da sociedade a propriedade foi adquirindo características que melhor se adaptavam com as necessidades de cada época. Passou da concepção absolutista e perpétua para visão mais social, com a incorporação do princípio da função social. Através da função social da propriedade o Estado adquiriu meios constitucionalmente protegidos de intervir na propriedade particular, entre eles, a desapropriação.

Nota-se que a Constituição garante o direito de propriedade, bem como exige que esta atenda a sua função social. Caso o particular não esteja utilizando, de forma adequada o bem, ou mesmo, esse seja importante para a realização de uma necessidade pública, a própria Constituição permite que a Administração Pública utilize-se da desapropriação para atingir o bem comum. No entanto, o Poder Público não possui a prerrogativa de utilizar-se desse meio interventivo ao bel prazer, faz-se necessário que atenda aos requisitos constitucionais da necessidade ou utilidade pública ou interesse social.

1 Este ensaio teve por referência Trabalho de Conclusão de Curso apresentado ao Curso de Direito da Universidade Estadual de Londrina, de autoria da primeira sob a orientação da segunda.

Aluna do 5o ano de Direito da Universidade Estadual de Londrina

Doutora em Direito do Estado - Direito Tributário pela PUC-SP. Professora de Direito Tributário na graduação do Curso de Direito da Universidade Estadual de Londrina e dos programas de Mestrado em Direito da Universidade Estadual de Londrina e da Universidade de Marília. 
Uma vez a desapropriação concluída, o Poder Público fica responsável por empregar ao bem afetado a devida destinação pública para a qual foi desejada. Caso esse fim não seja atingido, e ao bem for dado destino diverso e sem vinculação com o interesse social, caberá ao ex-proprietário reivindicar pelo imóvel, trata-se nesse caso do exercício do direito de retrocessão.

O direito de retrocessão possui vinculação direta com a motivação estabelecida no ato expropriatório, pois, caberá ao particular fazer uso desse instituto, quando ocorrer o desvio de finalidade, ou seja, quando a Administração Pública não utilizar o bem para fins de necessidade social, repassando o bem para terceiros, sem que estes tenham interesse em aplicar um fim público ao bem.

Nesse caso estará, o particular, ao pleitear o imóvel exercitando o direito de retrocessão que indiretamente é protegido pela Constituição Federal, pois, esta garante a propriedade como direito fundamental, bem como estabelece as hipóteses em que o Poder Público poderá intervir na propriedade particular por meio da desapropriação. Apesar dessa proteção indireta fornecida pela Carta Magna, o direito de retrocessão apresenta inúmeras discussões entre os doutrinadores, que envolvem desde questões relacionadas a sua natureza jurídica até em quais hipóteses poderá o particular recorrer a este instituto.

\section{Noções fundamentais sobre o direito de retrocessão}

Com o nascimento do Estado Social, foi incorporado ao instituto da propriedade privada o princípio da função social, o qual, permitiu a intervenção do Poder Público no bem particular. Entre as formas de intromissão da propriedade, que o Estado dispõe o instituto da desapropriação é a forma mais drástica de intervenção, visto que, tem como objetivo transferir o bem particular para o acervo dos bens públicos, dando a este uma destinação pública, ou seja, que venha a atender a necessidade da sociedade.

Conforme explica Celso Antônio Bandeira de Mello a desapropriação consiste no:

[...] procedimento através do qual o Poder Público, fundado em necessidade pública, utilidade pública ou interesse social, compulsoriamente despoja alguém de um bem certo, normalmente adquirindo-o para si, em caráter originário, mediante indenização prévia, justa e pagável em dinheiro, salvo no caso de certos imóveis urbanos ou rurais, em que, por estarem em desacordo com a função social legalmente caracterizada para eles, a indenização far-se-á em títulos da dívida 
pública, resgatáveis em parcelas anuais e sucessivas, preservado seu valor real. (MELLO, 2004, p. 758-759)

Procedida à desapropriação, e uma vez verificado que os requisitos constitucionalmente exigidos não foram respeitados pelo Poder Público surge o direito de retrocessão.

Ao se analisar o conceito de retrocessão, percebe-se que não há grandes divergências entre os doutrinadores ao definirem o instituto da retrocessão.

Maria Sylvia Zanella Di Pietro define o instituto como sendo "o direito que tem o expropriado de exigir de volta o seu imóvel caso o mesmo não tenha o destino para que se desapropriou". (DI PIETRO, 2004, p. 179)

Nota-se que o direito de retrocesso é inerente ao ex-proprietário, que teve seu bem declarado de utilidade pública pelo Poder Público, o qual, não deu ao imóvel a devida destinação para o qual foi desapropriado.

Cumpre ressaltar que o direito de retrocessão fora disciplinado no antigo Código Civil no art. 1150, o qual dispunha o seguinte:

Art. 1150. A União, o Estado, ou o Município, oferecerá ao ex-proprietário o imóvel desapropriado, pelo preço por que o foi, caso não tenha o destino, para que se desapropriou.

O novo Código Civil, no artigo 519, manteve a estrutura básica do instituto, embora tenha introduzido alterações que o tornaram mais claro e atual. Dispõe o art. 519 do Código Civil: (CARVALHO FILHO, 2005, p. 795)

Art. 519. Se a coisa expropriada para fins de necessidade ou utilidade pública, ou por interesse social, não tiver o destino para que se desapropriou, ou não for utilizada em obras ou serviços públicos, caberá ao expropriante direito de preferência, pelo preço atual da coisa.

Ao se analisar o texto trazido pelo novo Código Civil percebe-se que o artigo 519 trouxe uma inovação significativa em relação ao Código anterior. Ou seja, o Código anterior apenas mencionava quanto à destinação a ser dada ao bem desapropriado. Todavia, o Código atual acrescentou um importante suporte ao direito de retrocessão. Os dois elementos contidos no referido artigo são os seguintes: $1^{\circ}$ ) o bem não ter o destino para o 
qual foi desapropriado; 2으 o bem não ser utilizado em obras ou serviços públicos. (CARVALHO FILHO, 2005, p. 795)

Quanto a esses elementos introduzidos pelo novo Código Civil, José dos Santos Carvalho Filho explica que esse dispositivo aplica-se a todas as modalidades de desapropriação, seja por necessidade ou utilidade pública, ou interesse social. Sendo, ainda, de relevante importância:

\begin{abstract}
que o bem desapropriado não tenha o destino anteriormente projetado; nem tampouco, tenha utilização para obras ou serviços públicos. Significa dizer que, ainda que a finalidade não seja rigorosamente a que fora planejada antes, poderá o bem expropriado ser utilizado para fins públicos - obras e serviços -, sucedendo, então, o que a doutrina convencionou denominar de tredestinação lícita, vale dizer, alteração da finalidade inicial para outra finalidade pública - entendimento, diga-se de passagem, já há muito adotado por jurista e tribunais. (CARVALHO FILHO, 2005, p. 796)
\end{abstract}

O que diz respeito ao desvio de finalidade empregado ao bem desapropriado, esse será objeto de análise do próximo tópico. Cumpre agora, analisar as controvérsias quanto à natureza jurídica do direito de retrocessão, visto que, essa não é unânime entre os autores.

Sobre a questão da natureza jurídica da retrocessão explica Maria Sylvia Zanella Di Pietro, que há três correntes que discutem sobre esse assunto, entretanto, às três correntes são anteriores ao Código Civil de 2002.

A primeira corrente acredita que o direito de retrocessão não existe mais no ordenamento jurídico brasileiro como direito real. Alega que a retrocessão possui apenas caráter de direito pessoal, ou seja, o ex-proprietário poderá pleitear perdas e danos somente. Essa tese encontra-se fundamentada no artigo 1.150 do Código Civil de 1916 e no artigo 519 do atual Código Civil. Invocam, ainda, o artigo 35 do Decreto no 3.365/41, que não permite a reivindicação dos bens já incorporados ao patrimônio público. Por isso, afirmam que a retrocessão possui natureza de direito obrigacional, e não real. (DI PIETRO, 2004, p. 179)

A segunda corrente entende que o direito de retrocessão permanece como direito real, garantindo ao proprietário reivindicar pelo bem expropriado. Essa corrente baseia-se no artigo 5, XXIV do texto constitucional que garante o direito de propriedade como direito básico, e que só autoriza a desapropriação, quando essa medida for destinada a atender ao interesse coletivo. Caso o bem não seja utilizado para atender uma finalidade pública, 
desaparecerá a justificativa para a expropriação feita pelo Poder Público, cabendo ao exproprietário o direito de reaver o bem pelo preço, pelo qual foi desapropriado. (MELLO, 2004, p. 787)

A terceira corrente aceita a retrocessão como sendo de natureza mista (pessoal e real). Essa tese fundamenta a retrocessão alegando que o ex-proprietário possui o direito de pleitear tanto por perdas e danos quanto pelo bem afetado pela desapropriação. Conforme explica Celso Antônio Bandeira de Mello, esse posicionamento é equivocado, pois não há direito de natureza mista como afirmam os seguidores dessa corrente. $E$, ainda, nesse caso há dois direitos perfeitamente distintos, sendo que um exclui automaticamente o outro. (MELLO, 2004, p. 789)

Conclui a professora Di Pietro que a terceira corrente seria a mais indicada a ser aplicada ao instituto da retrocessão, quando analisada sob a ótica do artigo 1150 do Código Civil de 1916, através do qual a retrocessão seria direito real, ordenando, que o expropriante oferecesse de volta o bem expropriado. Entretanto, seria analisada como um direito pessoal, quando não fosse possível devolver o bem desapropriado, garantindo ao proprietário pleitear a indenização por perdas e danos sofridos. (DI PIETRO, 2004, p. 180)

A tese da retrocessão, com natureza de direito pessoal, que possui como base o artigo 519 do Código Civil, possivelmente, prevalecerá em detrimento das demais. Isto ocorrerá, face ao conteúdo do artigo 519 do Código Civil, o qual não estabelece mais que o poder expropriante ofereça o imóvel ao ex-proprietário, apenas assegura ao expropriado o direito de preferência, pelo preço atual do imóvel. (DI PIETRO, 2004, p. 180)

Esse não é o entendimento do professor Celso Antônio Bandeira de Mello. Para este autor a retrocessão possui natureza de direito real, face ao princípio da supremacia da Constituição, ou seja, nenhuma lei "poderia dar à matéria tratamento que contraditasse o que é simples resultado da proteção que a Lei Magna outorga à propriedade". (MELLO, 2004, p. 787)

Como já mencionado não há um consenso entre os autores sobre qual a melhor tese a ser aplicada ao direito de retrocessão, isto significa, que cada autor adota a tese que melhor se amolda ao seu entendimento. A tese adotada pelo professor Celso Antônio Bandeira de Mello, bem como Maria Sylvia Zanella Di Pietro é a tese que disciplina a retrocessão como sendo um direito real, pois, nas palavras da professora Di Pietro: 
não obstante a redação do novo Código Civil, ainda fico com a corrente que utiliza o argumento supra-referido, de ordem constitucional, pois o Código Civil não tem o condão de infringir a norma da Constituição que só permite a desapropriação por motivo de necessidade pública, utilidade pública ou interesse social. Demonstrando que o imóvel não foi utilizado nessa conformidade, o direito de propriedade do expropriado se restabelece em sua totalidade, com o direito à reivindicação do imóvel. (DI PIETRO, 2004, p. 181)

A retrocessão é um direito do proprietário de reaver o bem desapropriado, quando este não estiver cumprindo a função para a qual foi designada pelo Poder Público, independentemente de não haver um consenso entre os autores sobre a natureza jurídica desse instituto, visto ser a Constituição a lei suprema do país. Para que o particular possa invocar o direito de retrocessão a ele garantido, mister faz-se que o Poder Público não tenha dado a devida destinação ao bem desapropriado, ou seja, que tenha ocorrido o desvio de finalidade para o qual foi declarado.

\section{Situações que autorizam o particular a invocar o direito de retrocessão}

Como mencionado no tópico anterior, o particular poderá invocar o direito de reaver o bem desapropriado, quando a este for dada destinação diferente da mencionado no ato declaratório, que iniciou a expropriação. Desta forma, nota-se que a palavra chave do instituto da retrocessão é desvio de finalidade.

Mas, o que seria o desvio de finalidade?

De acordo com o artigo 2ํ, parágrafo único, "e" da Lei nํ 4.717/65:

Art. 2․ São nulos os atos lesivos ao patrimônio das entidades mencionadas no artigo anterior, nos casos de:

e) desvio de finalidade.

Parágrafo único. Para a conceituação dos casos de nulidade observar-se-ão as seguintes normas:

e) o desvio de finalidade se verifica quando o agente pratica o ato visando a fim diverso daquele previsto, explícita ou implicitamente, na regra de competência. (grifo nosso)

Seguindo o que está estabelecido na Lei, o professor Helly Lopes Meirelles discorre que o desvio de finalidade "ocorre, na desapropriação, quando o bem expropriado para um fim é empregado noutro sem utilidade pública ou interesse social. Daí o chamar-se, 
vulgarmente, a essa mudança de destinação, tredestinação para indicar o mau emprego do bem expropriado". (MEIRELLES, 2004, p. 597)

Conclui-se que o desvio de finalidade ocorre quando o bem deveria ser utilizado para atender a uma necessidade da população, e, no entanto, este está sendo empregado para outras finalidades que não possuem características de utilidade pública. E, ainda, conforme Helly Lopes Meirelles discorre o seguinte:

não pode haver expropriação por interesse privado de pessoa física ou entidade particular sem utilidade pública ou interesse social. $O$ interesse há que ser ou do Poder Público ou da coletividade beneficiada com o bem expropriado, pena de nulidade da desapropriação. (MEIRELLES, 2004, p. 597)

Como pressuposto básico da desapropriação, a finalidade pública destinada ao bem deve ser sempre analisada de forma genérica, isso ocorre, justamente porque se o bem expropriado for empregado de forma a atender aos interesses coletivos, mesmo que esse fim seja diverso do declarado pelo Poder Público não estará, desta forma, caracterizada o desvio de finalidade. (MEIRELLES, 2004, p. 597)

Hely Lopes Meirelles quando discorre sobre o desvio de finalidade apresenta o seguinte exemplo:

um terreno desapropriado para escola pública poderá, legitimamente, ser utilizado para construção de um pronto-socorro público sem que isto importe desvio de finalidade, mas não poderá ser alienado a uma organização privada para nele edificar uma escola ou um hospital particular, porque a estes faltaria a finalidade pública justificadora do ato expropriatório. (MEIRELLES, 2004, p. 597-598)

Mesmo quando a Administração Pública utiliza o imóvel para outra finalidade para o qual foi desapropriado, mas sendo esta consoante com o interesse público, não cabe falar em desvio de finalidade, pois, este se caracterizará quando a destinação do bem é desconforme com o interesse público.

De acordo com José dos Santos Carvalho Filho:

a retrocessão se relaciona com a tredestinação ilícita, qual seja, aquela pela qual o Estado, desistindo dos fins da desapropriação, transfere a terceiro o bem desapropriado ou pratica desvio de finalidade, permitindo que alguém se beneficie de sua utilização. Esses aspectos denotam realmente a desistência da desapropriação. (CARVALHO FILHO, 2005, p. 798) 
Percebe-se que o ato declaratório da desapropriação poderá ser anulado ou se sujeitar à retrocessão, quando o Poder Público ou seus delegados não derem ao bem expropriado a destinação para o qual foi requisitado. (MEIRELEs, 2004, p. 798)

Porém, a partir de que momento pode-se afirmar que o expropriante desistiu de empregar ao bem a finalidade pública inicialmente declarada?

Celso Antônio Bandeira de Mello discorre que existem dois posicionamentos sobre esse assunto. Para alguns a desistência irá se caracterizar dentro do prazo de 5 (cinco) anos contados da declaração de utilidade pública, ou seja, no decorrer desse período ao bem deve ser dado a destinação pública para o qual foi requisitado pelo Poder Público, e subtraído do domínio particular. Para outros, entre eles Celso Antônio, a desistência deve ser analisada caso a caso e sob a óptica dos fatos concretos. Esse entendimento é o predominante entre os doutrinadores. (MELLO, 2004, p. 791)

Caracterizado o desvio de finalidade caberá ao ex-proprietário pleitear a anulação do ato expropriatório, bem como que o bem seja devolvido. Cumpre ressaltar que esse desvio deve ser para fins não públicos, pois, como já analisado se houver uma destinação diferente da que foi declarada, mas atendendo as necessidades públicas, não se pode enquadrar na hipótese de desvio de finalidade.

Há uma situação, na qual o proprietário não terá direito à retrocessão, tratase da hipótese prevista no artigo 5으, §3으 do Decreto-lei no 3.365/41, alterado pela Lei 9.785/99. O referido artigo "dispôs que em casos de desapropriação para implantação de parcelamento popular, destinado às classes de menor renda, não se dará outra utilização, nem haverá retrocessão". (MEIRELLES, 2004, p. 799)

Quando o Poder Público não cumpre com seu papel de dar a devida utilização para o bem, surge o direito do particular de reaver o imóvel, que não está cumprindo a função a ele destinada. Como já mencionado, no que diz respeito ao direito do particular reaver o bem não é unânime entre os autores, face às divergências encontradas quanto à natureza do instituto. Com isso, surgem dúvidas quanto à real eficácia do direito de retrocessão. 


\subsection{Eficácia da retrocessão frente ao Artigo 35 do Decreto-lei no 3.365/41}

Dentro do contexto do instituto da desapropriação, a questão que envolve o direito de retrocessão pelo particular ganha real destaque, visto esse assunto ser controverso entre os autores.

Vale ressaltar primeiramente, que o direito de retrocessão está implicitamente protegido pela Carta Constitucional em seu artigo 5ㅇ, inciso XXII, quando eleva o direito a propriedade como sendo um direito fundamental. Todavia, a Constituição exige que esta esteja cumprindo com sua função social, caso contrário, ensejaria ao Poder Público intervir na propriedade como forma de evitar a ociosidade dos bens.

Entre todas as formas a disposição do Poder Público para intervir na propriedade particular, a desapropriação é a forma mais drástica, por isso mesmo, para que esta se efetive, o Poder Público precisa necessariamente respeitar e cumprir com os fundamentos constitucionais que autorizam a intervenção por parte da Administração Pública na propriedade particular.

Cumpre ressaltar, que somente quando ocorrer um desvio de finalidade será válido ao proprietário pleitear 0 direito de retrocessão, caso 0 bem não tenha a destinaçãoespecificada no ato expropriatório, mas se estiver sendo empregada para um fim público, não caracterizará desta forma o desvio de finalidade. Para fins de retrocessão, faz-se necessário que ao bem seja dado uma destinação totalmente desvinculada do interesse público.

Partindo da hipótese que ao bem foi dada destinação diferente da declarada e sem vinculação com interesses coletivos, é garantido ao ex-proprietário reaver o bem para si. Contudo, quando o direito de retrocessão é invocado pelo particular surgem algumas controvérsias a respeito do tema.

Essas divergências, entre os doutrinadores, ocorrem basicamente em razão de dois fatores, que são: 1) o período que caberia ao Poder Público dar a destinação ao bem; e 2) o conteúdo do artigo 35 do Decreto-lei no 3.365/41, o qual, determina que os bens uma vez incorporados ao patrimônio público não podem ser objeto de reivindicação.

Sobre o prazo concedido à Administração Pública para que promova a utilização do bem dispõe o artigo 10으 da Lei Geral da Desapropriação: 
Art. 10․ A desapropriação deverá efetivar-se mediante acordo ou intentar-se judicialmente dentro de 5 (cinco) anos, contados da data da expedição do respectivo decreto e findos os quais este caducará.

Baseando-se nesse fundamento que para alguns autores, quando o Poder Público não utilizar o bem dentro desse período de 5 (cinco) anos estará caracterizando a desistência por parte deste, gerando, conseqüentemente o direito de retrocessão do exproprietário. (CARVALHO FILHO, 2005, p. 799)

Posicionou-se, nesse sentido, Celso Antônio Bandeira de Mello, quando discorreu que:

violado o direito de preferência, o expropriado dispõe de cinco anos para intentar a ação de retrocessão pleiteando perdas e danos. Isto porque, conforme dispõe o Decreto 20.910, de 6.1.32, em seu art. 10: “As dívidas passivas da União, Estados e dos Municípios, bem assim todo e qualquer direito ou ação contra a Fazenda Federal, estadual, ou municipal, seja qual for sua natureza, prescrevem em cinco anos, contados da data do ato ou fato do qual se originaram. (MELLO, 2004, p. 792793)

De acordo com o artigo 205 do novo Código Civil, a prescrição ocorrerá em 10 (dez) anos, quando a lei não the fixar nenhum prazo menor. Conclui-se que não houve distinção entre ações reais e pessoais para fins de fixação do prazo prescricional, e que este passará a ser de 10 (dez) anos em qualquer hipótese.

Maria Sylvia Zanella Di Pietro escreve que essa nova norma, referente à prescrição dentro da retrocessão, com o decorrer do tempo será adaptada pelo Supremo Tribunal Federal, passando a ser aceito o prazo de 10 (dez) anos, desde que mantido a retrocessão como direito real. Alerta, ainda, que se esse não for o entendimento adotado, o prazo será qüinqüenal. (DI PIETRO, 2004, p. 181)

Já o entendimento de José dos Santos Carvalho Filho é de que:

inexiste essa presunção de desistência, já que a lei nada estabelece a respeito de prazo para a implementação do fim expropriatório. É o melhor enfoque, a nosso ver. De fato, a só inação do expropriante não significa, por si só, que tenha desistido da desapropriação. A desistência, como vimos, tem que estar plenamente caracterizada, ou seja, é preciso que a situação fática demonstre claramente que o expropriante não mais deseja destinar o bem a um fim público. E isso, é lógico, nem sempre decorre do fato de não se ter deflagrado a execução dos objetivos planejados. (CARVALHO FILHO, 2005, p. 799-800) 
Caberá ao ex-proprietário reivindicar o bem desapropriado, quando ocorrer o desvio de finalidade no período de 5 (cinco) anos da declaração expropriatória. Entretanto, faz-se necessário que seja transparente o:

ato que denuncie o desinteresse do expropriante, como a doação, a venda, a troca, o completo abandono, a deterioração, a tolerância ante esbulhos ou invasões, nasce o direito à retrocessão. (RIZZARDO, 2004, p. 449)

Após, estabelecido o prazo para a destinação do bem, sendo este o mesmo para que o ex-proprietário reivindique o bem, cumpre agora analisar a questão que envolve o artigo 35 do Decreto-lei no 3.365/41. Esse artigo dispõe o seguinte:

Art. 35. Os bens expropriados, uma vez incorporados à fazenda Pública, não podem ser objeto de reivindicação, ainda que fundada em nulidade do processo de desapropriação. Qualquer ação, julgada procedente, resolver-se-á em perdas e danos.

Diante do conteúdo desse artigo surgem inúmeras divergências entre os doutrinadores a respeito do direito de retrocessão. Para alguns autores, a retrocessão é tida como um direito pessoal não podendo o bem ser pleiteado pelo ex-proprietário, e a este caberá somente reivindicar as perdas e danos sofridos.

Entre os autores que seguem esse posicionamento esta José dos Santos Carvalho Filho, que discorre sobre o tema o seguinte:

o instituto da retrocessão não existe no ordenamento jurídico; o que existe é o direito pessoal do expropriado de postular indenização. O argumento mais poderoso dessa corrente de pensamento está na própria posição do art. 519 do Código Civil. Situa-se o dispositivo no capítulo relativo à preempção ou preferência, matéria típica do direito obrigacional, que se resolve em perdas e danos, numa evidente demonstração de que disciplinam direitos pessoais. (CARVALHO FILHO, 2005, p. 797)

Corroborando com essa tese escreve José Rodrigues Arimatéa o seguinte "mesmo sendo direito do expropriado pedir a devolução do bem, se o Poder Público não aceitar fazer a devolução do bem, nada resta ao proprietário senão ajuizar ação indenizatória das perdas e danos que tenha experimentado". (ARIMATÉA, 2003, p. 133) 
Ainda, no entendimento de Arimatéa, o direito de retrocessão está intimamente ligado ao direito de preferência, preempção ou prelação legal, ou seja, esses institutos encontram-se disciplinados no artigo 513 do Código Civil, que dispõe o seguinte:

Art. 513. A preempção, ou preferência, impõe ao comprador a obrigação de oferecer ao vendedor a coisa que aquele vai vender, ou dar em pagamento, para que este use de seu direito de prelação na compra, tanto por tanto.

Percebe-se que esses institutos poderão ser utilizados pelo particular, quando o Poder Público, após a consumação da desapropriação, não der ao bem expropriado a destinação prevista no Decreto expropriatório, pretendendo, desta forma, vendê-lo, seja porque cessou a sua necessidade ou utilidade pública ou interesse social. Nesta hipótese, o Estado terá que oferecê-lo ao expropriado, que tem o direito de preferência para a sua aquisição. (ARIMATÉA, 2003, p. 134)

Entretanto, afirma Arimatéa, que conforme determina o artigo 2o da Lei $\mathrm{n}$ 은 8.666/93 (Lei das Licitações),

as alienações feitas pela Administração Pública devem ser precedidas de licitação. Assim, se a Administração Pública pretender vender o bem expropriado, terá de fazê-lo mediante licitação pública, o que a impede de satisfazer o direito de preferência conferido ao expropriado, salvo em igualdade de condições. Por isso, a inobservância do direito de preferência conferido ao expropriado resolve-se em perdas e danos. (ARIMATÉA, 2003, p. 134)

Outro argumento muito utilizado pelos doutrinadores que afirmam, que o direito de retrocessão trata-se de um direito pessoal, é o conteúdo estabelecido no artigo 35 do Decreto-lei no 3.365/41. Isso ocorre, pois o referido artigo ao estatuir que o ex-proprietário perde seu direito de reivindicar o bem, mesmo quando o processo de desapropriação seja declarado nulo, em face, da lei considerar definitivamente incorporado o bem ao patrimônio público. Desse modo, "o ex-proprietário não poderia ter o direito real de reaver a coisa, mas apenas o direito pessoal de pleitear indenização, provando que sofreu prejuízo com a superveniente desistência do Poder Público, de dar a devida destinação ao bem desapropriado". (CARVALHO FILHO, 2005, p. 799)

Baseando-se nesses argumentos, a tese que defende a retrocessão como sendo um direito pessoal afirma que ao proprietário não é permitido pleitear o bem desapropriado de 
volta, a este caberá somente reivindicar por perdas e danos, seja porque o próprio Decretolei que regulamenta a desapropriação veda tal procedimento, ou como mencionado por José Rodrigues Arimatéa, qualquer alienação feita pelo Poder Público necessitará de processo licitatório, mesmo sendo um direito do proprietário de pleitear pelo bem desapropriado que não está cumprindo a função para o qual foi destinado.

Contrariando essa tese, têm-se os doutrinadores que defendem o direito de retrocessão como sendo de direito real, ou seja, compete ao expropriado reaver o bem nos casos de desvio de finalidade.

Quando o assunto é retrocessão por desvio de finalidade, tem sido predominante o entendimento de ser esse direito caracterizado como de direito real. Conseqüentemente, concedido ao ex-proprietário reaver o bem. Foi esse o posicionamento do STJ ao julgar recurso especial apresentado pelo Poder Público na tentativa de não ter o direito de retrocessão reconhecido, por ter repassado o terreno desapropriado para terceiro, que o utilizava para a atividade de borracharia, conforme se verifica com a ementa do julgado a seguir:

RETROCESSÃO - DESVIO DE FINALIDADE PÚBLICA DE BEM DESAPROPRIADO CONDENAÇÃO DO MUNICÍPIO À DEVOLUÇÃO DO BEM MEDIANTE O RESSARCIMENTO DA INDENIZAÇÃO RECEBIDA PELA EXPROPRIADA. ( BRASIL. Superior Tribunal de Justiça. Deferimento do Recurso Especial. Caracterizado o Desvio de Finalidade. Relator: Ministro Luiz Fux.

Brasília, 06 de junho de 2005.Disponível em www.stj.gov.br, acessado em 27/05/06)

Presente o referido requisito, os tribunais têm decido favoravelmente em decretar nulo o ato expropriatório e reintegrarem os antigos proprietários ao bem afetado. Foi partindo da mesma premissa do desvio de finalidade, ao analisar a questão de determinada área, decretada de utilidade pública, para a construção de parque industrial, que estava sendo utilizada como depósito de lixo por uma empresa particular, que o Tribunal de Justiça do Paraná decidiu por reconhecer o ato como nulo e decretar que o antigo proprietário retornasse ao bem, do qual foi despojado pelo Poder Público. O caso mencionado é o seguinte:

AÇÃO DE NULIDADE DE ATO JURÍDICO, CUMULADA COM INDENIZAÇÃO. DECRETO DE DESAPROPRIAÇÃO DE ÁREAS RURAIS. 
DESVIO DE FINALIDADE COMPROVADA. PROCEDÊNCIA PARCIAL. DECISÃO CONFIRMADA. 1. Restando demonstrado que, na desapropriação de terras rurais, para fins de ampliação de distrito industrial, ocorreu desvio de finalidade (houve permissão provisória para empresa adentrar em parcela da área, que, posteriormente, a vendeu a terceiro; não foram implantas indústrias e, decorridos mais de quatro (4) anos, o imóvel foi transformado em depósito de liso), viável a ação direta para invalidar aquele ato administrativo. 2. Nesse caso, sendo comprovada a existência do apontado vício, julga-se procedente a ação para decretar a nulidade do ato de desapropriação, reintegrar os autores na posse do imóvel e condenar o réu a indenizar lucros cessantes. (BRASIL. Tribunal de Justiça do Paraná. Deferimento de Apelação Cível. Ação de Nulidade de Ato Jurídico. Relator: Desembargador Accácio Cambi. Curitiba, 24 de junho de 1998. Disponível em www.tj.pr.gov.br, acessado em 27/05/2006.).

Conforme discorre a professora Maria Sylvia Zanella Di Pietro, o argumento sustentador dessa tese encontra-se fundamentado na própria Constituição, na qual, encontra-se sobre quais bens poderá recair a desapropriação, bem como as hipóteses em que pode ser declara e fundamentada a desapropriação. (DI PIETRO, 2004, p. 181)

Esse fato decorre do próprio texto Constitucional, conforme explica Celso Antônio Bandeira de Mello o seguinte:

configura o direito de propriedade como direito básico, que só deve ceder à demissão compulsória para a realização de uma finalidade pública. Donde, em vista do princípio da supremacia da Constituição, lei alguma poderia dar à matéria tratamento que contraditasse o que é simples resultado da proteção que a Lei Magna outorga à propriedade, já que a garantia que lhe confere só é absolvida para satisfação de uma finalidade pública. Daí a impotência da invocação do art. 1150 do Código Civil anterior (ou do atual, art. 519) para arrimar entendimento diverso, ou do art. 35 do Decreto-lei 3.365 para infirmar - nos casos em que caiba o direito ao retorno do bem ao expropriado. (MELLO, 2004, p. 787)

Percebe-se que ambas as teses possuem fundamentação coesa, porém, não seria coerente estabelecer a retrocessão apenas como sendo um direito pessoal, que se resumirá em perdas e danos, simplesmente pelo fato do Código Civil assim ter estabelecido no Art. 519, caso ocorra o desvio de finalidade, caberá ao proprietário somente reivindicar perdas e danos.

Acredita-se que o Código Civil não tem o condão de infringir a norma da Constituição, motivo esse porque se tende a aceitar a retrocessão como sendo um direito real. Ou seja, respeitando o direito do particular de reaver o bem, quando houver fatos comprovando o real desinteresse do Poder Público em destinar ao bem a finalidade para o qual foi declarado. 
A retrocessão aparece como um instituto protetor do direito de propriedade dentro do processo expropriatório, pois, a propriedade é estabelecida no texto constitucional dentro dos direitos fundamentais, e como tais são irrenunciáveis e conseqüentemente invioláveis, entretanto, a propriedade pode sofrer essa violação por parte de Poder Público, em face do interesse coletivo, respeitando o princípio constitucional da função social. Para que a propriedade sofra essa intervenção a Administração Pública precisa necessariamente atender aos fundamentos constitucionais e realmente aplicar ao imóvel um fim público.

Quando verificado esse desvio na destinação do bem desapropriado cabe ao exproprietário reaver o bem para si, pois, se trata de um direito fundamental a ele garantido pela Carta Magna, não devendo prevalecer à hipótese que apenas garante ao particular pleitear por perdas e danos como alguns autores entendem.

\section{Considerações finais}

A Constituição Federal elevou a propriedade à condição de direito fundamental, porém, exigiu que a mesma atendesse a sua função social. Com essa proteção fornecida pela Carta Magna, o bem particular adquiriu a possibilidade de ser limitado pelo Poder Público, através dos meios interventivos, que possui a sua disposição para fazer cumprir essa exigência constitucional.

Para que $\mathrm{o}$ ato interventivo do Estado não seja considerado arbitrário faz-se necessário que o mesmo venha devidamente fundamentado em uma das hipóteses autorizadoras previstas na legislação federal, quais sejam: necessidade ou utilidade pública, ou interesse social.

A Constituição garante o direito de propriedade, todavia, para atender aos interesses coletivos face aos individuais, ela permite que o Poder Público desaproprie determinado bem para dar a este uma finalidade pública. Mas uma vez caracterizado o desvio de finalidade, caberá ao particular pleitear pela reintegração do bem afetado, recorrendo ao Poder Judiciário, o qual, possui o dever de fiscalizar os atos administrativos, para que estes não sejam utilizados de forma arbitraria aos preceitos constitucionais, causando danos aos direitos coletivos em geral, e não somente ao direito do ex-proprietário despojado de seu bem. 
Conforme se verificou no trabalho, a natureza jurídica do direito de retrocessão não é unânime entre os doutrinadores, sendo para uns de direito pessoal, restando ao exproprietário somente pleitear por perdas e danos. Já para a outra corrente, que possui o posicionamento majoritário e até mesmo o adotado pelos Tribunais Superiores, trata-se de direito real, através do qual, o particular possui o direito de reaver o bem para si, visto que, se trata de um direito protegido pela Carga Magna. Alegam, ainda, que todas as leis devem estar em conformidade com a Lei Maior do país, não podendo em qualquer hipótese contrariar os preceitos constitucionais.

A grande discussão suscitada em torno do direito de retrocessão surge da interpretação do artigo 35 do Decreto-Lei no 3.365/41, o qual, discorre que o bem desapropriado, uma vez incorporado à Fazenda Pública não poderá ser objeto de reivindicação, restando somente ao proprietário reclamar por perdas e danos, quando houver desvio de finalidade do bem.

Ocorre, porém, um choque entre o artigo 35 do referido Decreto e o posicionamento de recentes decisões jurisprudenciais, entendimentos doutrinários, e, principalmente com a Constituição Federal. Esse conflito tem surgido porque há o entendimento de conceder ao proprietário o direito de pleitear em juízo o bem afetado, toda vez que ficar caracterizado o desvio de finalidade para o qual o bem foi desapropriado. Trata-se de uma violação a norma constitucional, que protege o direito de propriedade como direito fundamental, permitindo ao Poder Público intervir na esfera particular somente quando estiver em questão interesses coletivos, ou seja, o bem comum da sociedade.

O direito de retrocessão deve ser entendido como um mecanismo de defesa, posto à disposição do particular, quando ao seu bem não for dada a devida destinação para o qual foi desapropriado. E, não ser visto como mero mecanismo de indenização a serviço do particular. Partindo desse entendimento, conclui-se que é cabível e constitucionalmente consagrado o direito de retrocessão quando houver desvio de finalidade na desapropriação

\section{Referências}

ANJOS, Luís Henrique Martins dos; ANJOS, Walter Jones dos. Manual de Direito Administrativo. Porto alegre: Livraria do Advogado, 2001. 
ARIMATÉA, José Rodrigues. O Direito de Propriedade. Limitações e Restrições Públicas. São Paulo: Lemos \& Cruz, 2003.

BASTOS, Celso Ribeiro. Curso de Direito Administrativo. 2. ed. São Paulo: Saraiva, 1996.

BASTOS, Celso Ribeiro. MARTINS, Ives Gandra. Comentários à Constituição do Brasil. V. 7 (arts. 170 a 192). São Paulo: Saraiva, 1990.

BOBBIO, Noberto. Estado, Governo, Sociedade. Para uma Teoria Geral da Política. 11. ed. Rio de Janeiro: Paz e Terra, 2004.

BONAVIDES, Paulo. Teoria do Estado. 5. ed. São Paulo: Malheiros, 2004.

CARVALHO FILHO, José dos Santos. Manual de direito Administrativo. 12. ed. Rio de Janeiro: Lúmen Júris, 2005.

FIQUEREDO, Lúcia Valle. Curso de Direito Administrativo. 7. ed. revista, atualizada e ampliada. São Paulo: Malheiros, 2004.

FREITAS, Juarez. O controle dos atos administrativos e os princípios fundamentais. 3. ed. São Paulo: Malheiros, 2004.

GASPARINI, Diógenes. Direito Administrativo. 9. ed. São Paulo: Saraiva, 2004.

MEDAUAR, Odete. Direito Administrativo Moderno. 8. ed., revista e atualizada. São Paulo: Revista dos Tribunais, 2004.

MEIRELLES, Hely Lopes. Direito Administrativo Brasileiro. 29. ed. São Paulo: Malheiros, 2004.

MELLO, Celso Antônio Bandeira de. Curso de Direito Administrativo. 17. ed. São Paulo: Malheiros, 2004.

MORAES, Alexandre. Direito Constitucional Administrativo. São Paulo: Atlas, 2002.

PIETRO, Maria Sylvia Zanella Di. Discricionariedade Administrativa na Constituição de 1988. 2. ed. São Paulo: Atlas S.A., 2001.

Direito Administrativo. 17. ed. atualizada com Reforma Previdenciária - EC 41/03.

São Paulo: Atlas S. A., 2004. 
RIZZARDO, Arnaldo. Direito das Coisas. Lei no 10.406, de 10.01.2002. Rio de Janeiro: Forense, 2004.

SILVA, José Afonso da. Curso de Direito Constitucional Positivo. 20. ed. São Paulo: Malheiros, 2002.

SUNDFELD, Carlos Ari. Fundamentos de Direito Público. 4. ed. São Paulo: Malheiros, 2002.

VENOSA, Sílvio de Salvo. Direito Civil. Direitos Reais. 4. ed. São Paulo: Atlas, 2004. v. 5. 